\title{
Design and Implementation of Op-Amp Based Low-Power CMOS Bandgap Voltage Reference with Minimum Supply oF 0.8-V
}

\author{
Arivazhagan P
}

\begin{abstract}
A low power voltage source is generated by altering the device size in existing topology has been presented. Bandgap voltage reference is generated by combination of start-up, supply independent, operational amplifier (Op-amp) and bandgap core circuits which has been designed such that low sensitivity of temperature and supply variation. It has been designed with minimum supply of $0.8 \mathrm{~V}$ without use of low threshold device, and the maximum supply current is $35 \mu \mathrm{A}$. It has been implemented in $180 \mathrm{~nm}$ standard digital CMOS Process. The circuit generates a reference voltage of $540 \mathrm{mV}$ and has a temperature coefficient of 14 ppm $1{ }^{\circ} \mathrm{C}$ from $-40{ }^{\circ} \mathrm{C}$ to $120{ }^{\circ} \mathrm{C}$. The generated reference voltage is independent of temperature and supply variations have been mathematically proved by analyzing the circuit design. Also, proper selection of on-chip passive components and its values has been chosen which is based on low noise. Comparing the pre and post layout simulation results has been presented.
\end{abstract}

Keyword--- Gain Calculations, Device Mismatch, Temperature Independent Biasing, Supply Independent

\section{INTRODUCTION}

A reference circuit is used to generate a voltage, which is independent of supply voltage $\left(\mathrm{V}_{\mathrm{DD}}\right)$, and temperature variations $\left(\mathrm{V}_{\mathrm{T}}\right)$. It is one of the core functional blocks in both analog and digital systems and should be capable to operate as low as $1 \mathrm{~V}$ supply [1]. Today's wireless applications everything moves onto battery operated portable system. To make longer battery life time, a system needs to design such that it will consume low power. CMOS technology is the best choice to achieve these performances as it has low power consumption than other technology like BiCMOS etc., However, due to scaling down; the devices cannot operate much lower than $1 \mathrm{~V}$ supply in the near future. To overcome thisdifficulty, the transistor should capable to operate either in subthreshold region (or) increase the device sizes such that to reduce threshold voltage of transistor, which helps to operate in low supply voltage. The output voltage of the conventional bandage reference (BGR) is $1.25 \mathrm{~V}$, which is nearly equal to bandgap as $1 \mathrm{~V}$ supply.The output voltage of $1.25 \mathrm{~V}$ limits the low $\mathrm{V}_{\mathrm{DD}}$ operation. With the help of resistive subdivision [1] or by using BiCMOS process [2] or by using low threshold voltage devices [3], BGR circuit should be capable to operate as low as $1 \mathrm{~V}$ supply. In this design, resistive subdivision without using low threshold device is used to operate in 1 ' $\mathrm{V}$ ' supply in $0.18 \mu \mathrm{m}$ CMOS technology instead of $1.8 \mathrm{~V}$ by altering the device size of transistor.

This paper is organized as follows. Section 2 describes about the overview of all the sub-blocks which contains the proposed block diagram of bandgap reference. Section 3 proves that output current is independent of supply and temperature variations. Section 4 describes about bandgap reference followed by layout design and comparing pre and post layout results. Section 5 shows the final conclusion and future enhancement of this design.

\section{Block Diagram of Bandgap Reference}

The architecture of the reference generator block is shown in Fig.1. It includes the start-up, supply independent, CMOS Op-amp and bandgap core. The start-up is used to turn on the entire transistor which is incorporated in supply independent biasing circuit when the supply voltage varies from ' 0 ' to $V_{D D}$ during transients. Supply independent biasing circuit is used to generate the current reference for biasing the op-amp, which is independent of supply voltage $\left(\mathrm{V}_{\mathrm{DD}}\right)$ variations. Op-amp senses $\mathrm{V}_{\text {in- }}$ and $\mathrm{V}_{\mathrm{in}+}$, which is coming from bandgap core, then output of Op-amp is bandgap core as shown in Fig. 1 such that to stabilize the $\mathrm{V}_{\text {in- }}$ and $\mathrm{V}_{\text {in }}$ is approximately equal, which is independent of $\mathrm{V}_{\mathrm{T}}$. Op-amp needs to design with low power consumption, high stability during transients and device mismatch to make $V_{\text {in- }}$ and $V_{\text {in }+}$. Bandgap core is used to generate the voltage references, which is independent of $\mathrm{V}_{\mathrm{T}}$.

\footnotetext{
P. Arivazhagan, Assistant Professor, Department of Electronics and Communication Engineering, Kodaikanal Institute of Technology, Kodaikanal,Tamil Nadul,India E-mail:astm_codes@hotmail.com
} 


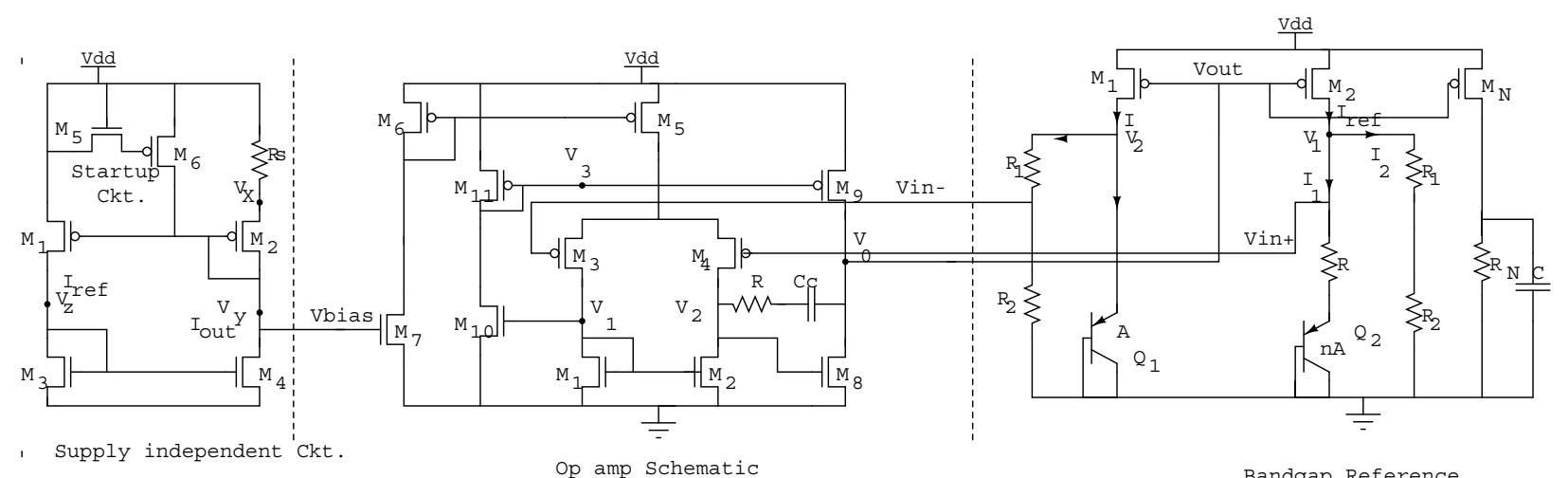

p amp Schematic

Bandgap Reference

Fig. 2: Schematic of Bandgap Core

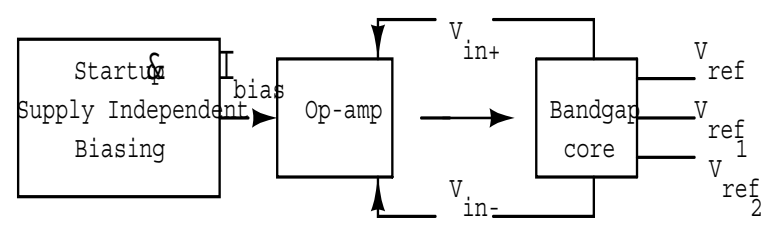

Fig. 1: Block Diagram of Bandgap Reference

\section{SupPly AND TEMPERATURE INDEPENDENT BIASING CURRENT}

\subsection{Supply Independent Biasing}

To generate the reference currents as this is independent of supply voltage $\left(\mathrm{V}_{\mathrm{DD}}\right)$ variations shown in Fig. 2 for biasing the subsequent blocks like Op-amp. The transistor $\mathrm{M}_{1}-\mathrm{M}_{4}$ designed such that it should operate in saturation region, whereas $\mathrm{M}_{2-3}$ is connected in diode configuration. The ' $R s$ ' called source degeneration resistance used for stabilize the $g_{m}$ variation is added in the supply independent circuit shown in Fig. 2 to make equalize current of nMOS transistors $\left(\mathrm{M}_{3}-\mathrm{M}_{4}\right)$ such that $\mathrm{I}_{\text {ref }}$ equal to $\mathrm{I}_{\text {out }}[4]$ instead of $\mathrm{I}_{\text {out }}$ equal to ' $\alpha$ ' times $\mathrm{I}_{\text {ref }}$ due to $R_{s}$.

\section{3..1.1 Calculation of Output Current}

At node $V_{x}$,

$$
V_{x}=V_{D D}-I_{\text {out }} R_{s}
$$

At node $V_{y}$,

$$
\begin{aligned}
& V_{y}=V_{x}-V_{s g 2}=V_{D D}-I_{\text {out }} R_{s}-V_{s g 2} \\
& V_{s g 1}=V_{s 1}-V_{g 1}\left(V_{y}\right)=I_{\text {out }} R_{s}+V_{s g 2}
\end{aligned}
$$

Equation (3) becomes,

$$
\begin{array}{r}
V_{s g 1}-V_{s g 2}=I_{o u t} R_{s} \\
\sqrt{\frac{2 I_{\text {out }}}{\mu_{p} C_{\text {ox }}\left(\frac{W}{L}\right)_{1}}}-\sqrt{\frac{2 I_{\text {out }}}{\mu_{p} C_{o x} \alpha\left(\frac{W}{L}\right)_{1}}}=I_{\text {out }} R_{s} \\
I_{\text {out }}=\frac{2}{\mu_{p} C_{\text {ox }}\left(\frac{W}{L}\right)_{1}} \frac{1}{R_{s}{ }^{2}}\left(1-\frac{2}{\sqrt{\alpha}}\right)^{2}
\end{array}
$$

Equation (5) is the output reference current, which shows that output current is independent of supply voltage variation but depends on temperature variations.

Condition for ' $\mathrm{M}_{1}$ ' \& ' $\mathrm{M}_{4}$ ' to be operated in saturation region shown in Fig. 2 is,

$$
\begin{aligned}
& V_{z} \leq V_{y}-\left|V_{t h p_{1}}\right| \leq V_{D D}-I_{\text {out }} R_{s}-V_{s g_{2}}-\left|V_{t h p_{1}}\right| \\
& V_{z} \leq V_{D D}-I_{\text {out }} R_{s}-\sqrt{\frac{2 I_{\text {out }}}{\mu_{p} C_{o x} \alpha\left(\frac{W}{L}\right)_{1}}} \\
& V_{y} \geq V_{z}-V_{t h n} 4
\end{aligned}
$$

\subsubsection{Analysis}

The small signal model of supply independent circuit is shown in Fig. 3 to estimate the output current to supply voltage $\left(I_{o u t} / V_{D D}\right)$. The term is called sensitivity factor.

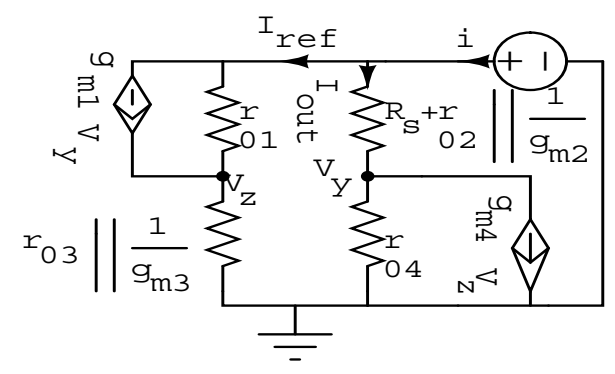

Fig. 3: Small Signal Model of Supply Independent Biasing Circuit

By Kirchoff's Current Law (KCL),

$$
\begin{gathered}
I=I_{\text {ref }}+I_{\text {out }} \\
I_{\text {ref }} \Rightarrow V_{D D}=\left(R_{s}+\left(\left(r_{02} \mid \frac{1}{g_{m 2}}\right)+r_{04}\right) I_{\text {ref }}-g_{m 4} V_{z} r_{04}\right)
\end{gathered}
$$

Where,

$$
V_{z}=I_{r e f}\left(r_{03} \| \frac{1}{g_{m 3}}\right)
$$

Equation (8) becomes, 


$$
\frac{V_{D D}}{I_{r e f}}=\left(R_{s}+\left(\left(r_{02} \| \frac{1}{g_{m 2}}\right)+r_{04}\right)-g_{m 4} r_{04}\left(r_{03} \| \frac{1}{g_{m 3}}\right)\right)=R_{01}
$$

Similarly, as shown in Fig 3,

$$
\begin{gathered}
\frac{V_{D D}}{I_{\text {out }}}=\left(r_{01}+\left(r_{03} \| \frac{1}{g_{m 3}}\right)+g_{m 1} g_{m 4}\left(r_{03} \| \frac{1}{g_{m 3}}\right)\left(r_{04}\right)-g_{m 1} r_{04}\right)=R_{02} \\
\frac{I_{\text {out }}}{V_{D D}}=\frac{1}{R_{01} \| R_{02}}-\frac{1}{R_{02}}
\end{gathered}
$$

Equation (11) shows the output current varies by $V_{D D}$ based on the values $R_{01}$ and $R_{02}$, as it chosen by design parameters.

\subsubsection{Startup Problem}

Startup problem defines as when the supply voltage is turned on; all the transistors which is incorporated to make system remain off as it have zero current. To solve this problem, the transistors ' $\mathrm{M}_{5-6}$ ' is connected closer to supply voltage. During transients, when supply voltage varies from ' 0 ' to ' $\mathrm{V}_{\mathrm{DD}}$ ', it generates the bias point at node $\mathrm{V}_{\mathrm{y}}$ by injecting amount of charges through transistor $\mathrm{M}_{5-6}$, to turn on the transistor ' $\mathrm{M}_{1}$ '. The transistor $\mathrm{M}_{1}$ gives the output reference current $\left(I_{r e f}\right)$ when $V_{S G 1}>V_{\text {thp1 }}$ then mirroring the current through $\mathrm{M}_{3-4}$ to turn on. The gate potential of transistor $\mathrm{M}_{4}$ reaches $\mathrm{V}_{\mathrm{GS} 4}>\mathrm{V}_{\mathrm{thn} 1}$, it will generate the output current $\left(\mathrm{I}_{\text {out }}\right)$ then mirroring $\mathrm{M}_{2}$ to $\mathrm{M}_{1}$. The process will continue until it reaches the maximum supply voltage $\mathrm{V}_{\mathrm{DD}}$. If it reach the $\mathrm{V}_{\mathrm{DD}}$, the condition for entire transistor, which is incorporated in supply independent circuit to operate in saturation region as it satisfy the equation (6) \& (7) at the same time $\mathrm{M}_{5-6}$ should be turn off.

\subsection{Principle of Operational Amplifier}

Fig. 2 shows a two stage Op-amp, where $\mathrm{M}_{3}$ and $\mathrm{M}_{4}$ acts as differential pMOS input pair, $\mathrm{M}_{1-2}$ acts as current mirror. $\mathrm{M}_{5}$ acts to generate the bias current based on mirroring the current through $\mathrm{M}_{6-7}$ used for biasing the differential pair. This topology is best suited for low voltage operation due to nobody effect and low flicker noise than differential nMOS input pair. $\mathrm{M}_{8-9}$ acts as single stage amplifier using active load to increase the gain. To biasing the transistor $\mathrm{M}_{9}$,

mirroring the current through $\mathrm{M}_{10-11}$. The resistance $(R)$ and compensation capacitor $(C c)$ used for compensation to make stability of the system as it introduce the zeros between poles.

\subsubsection{Analysis}

Fig. 4 shows the small signal model of op-amp shown in Fig. 2 to find the gain of the system. In the figure below, the subscript number 5,6,7,8 changes in

to $8,9,10$ and 11 i.e., $r_{05}=r_{08}$ by Fig. 2 .

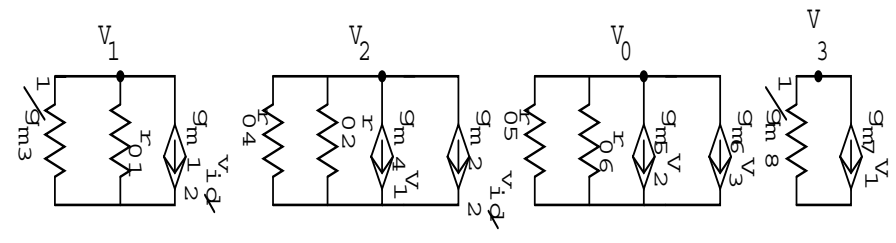

Fig. 4: Small Signal Model of Two Stage Miller Compensated Op Amp used in Band-Gap Reference

$$
\frac{V_{0}}{v_{i d}}=g_{m 8}\left(\frac{1+2 g_{m 2}\left(\frac{r_{02} \times r_{04}}{r_{02}+r_{04}}\right)}{2}\right)\left(\frac{r_{08} \times r_{09}}{r_{08}+r_{09}}\right)
$$

Equation (12) is the gain of the Operational amplifier.

\subsubsection{Device Mismatch}

To design a low systematic offset Op-amp for bandgap applications, device mismatch is major issue. In these design current drawn from $\mathrm{M}_{8}$ and $\mathrm{M}_{9}$ are perfectly matched as it depends on input arise from node $\mathrm{V}_{1} \& \mathrm{~V}_{2}$. The current relationship between $I_{8}$ and $I_{9}$ in terms of bias current $(I)$ is generated by $\mathrm{M}_{5}$.

$$
\frac{\left(\frac{W}{L}\right)_{8}}{\left(\frac{W}{L}\right)_{2}}=\frac{\left(\frac{W}{L}\right)_{9}}{\left(\frac{W}{L}\right)_{11}} \frac{\left(\frac{W}{L}\right)_{10}}{\left(\frac{W}{L}\right)_{1}}
$$

Equation (13) is device size relationship to get $I_{8}$ and $I_{9}$ are perfectly matched without delay difference.

\subsection{Temperature Independent Biasing}

To generate the reference voltage as it independent of temperature variation by adding the two currents as it depends on positive and negative temperature coefficient (TC). The resultant output is zero TC.

By KCL, at node $\left(\mathrm{V}_{1}\right)$ shown in Fig. 2 (bandgap reference) is,

$$
i_{r e f}=i_{1}+i_{2}
$$

Where,

$$
\begin{gathered}
i_{1}=\frac{V_{E B 1}-V_{E B 2}}{R}=\frac{V_{T} \ln n}{R} \\
i_{2}=\frac{V_{E B 1}}{R_{1}+R_{2}}
\end{gathered}
$$

Substitute (13) \& (14) in (12),

$$
i_{\text {ref }}=\frac{V_{T} \ln n}{R}+\frac{V_{E B 1}}{R_{1}+R_{2}}
$$

To make a design such that change in reference current to change in temperature is less sensitivity $(=0)$ based on the values of active and passive devices, which is used in the design.

Equation (15) becomes,

$$
\frac{d i_{r e f}}{d T}=\frac{d}{d T}\left(\frac{V_{T} \ln n}{R}\right)+\frac{d}{d T}\left(\frac{V_{E B 1}}{R_{1}+R_{2}}\right)=0
$$

Where,

$$
\begin{aligned}
& \frac{d}{d T}\left(\frac{V_{T} \ln n}{R}\right)=\frac{R \ln (n) \frac{d V_{T}}{d T}-V_{T} \ln (n)(T C R) R\left(T_{0}\right)}{R^{2}} \\
& \frac{d}{d T}\left(\frac{V_{E B 1}}{R_{1}+R_{2}}\right)=\frac{\left(R_{1}+R_{2}\right) \frac{d V_{E B 1}}{d T}-V_{E B 1}(T C R)\left(R_{1}\left(T_{0}\right)+R_{2}\left(T_{0}\right)\right)}{\left(R_{1}+R_{2}\right)^{2}}
\end{aligned}
$$


Assume all the design values at room temperature $\mathrm{T}=300^{\circ} \mathrm{K}$,

$$
\begin{aligned}
& \frac{d V_{T}}{d T}=0.08617 \mathrm{mV} /{ }^{\circ} \mathrm{K}, V_{T}=26 \mathrm{mV}, \\
& \text { TCR } \text { temperature coefficient of } P+\text { poly silicon }) \\
& =160 \mathrm{ppm} /{ }^{\circ} \mathrm{C}=0.0000006 /{ }^{\circ} \mathrm{K} .
\end{aligned}
$$

To make the node voltage at $\mathrm{V}_{1}$ and $\mathrm{V}_{2}$ is equal shown in Fig. 2 in bandgap reference. For that the size of transistor ' $\mathrm{Q}_{2}$ ' is ' $\mathrm{n}$ ' times the size of transistor " $\mathrm{Q}_{1}$ ". With various perceptive, chosen ' $n$ ' is equal to 8 .

Equation (6) becomes,

At room temperature,

$$
\begin{aligned}
& \mathrm{R}_{\mathrm{N}}=\mathrm{R}_{\mathrm{N}}\left(\mathrm{T}_{0}\right)\left(1+\mathrm{TCR}\left(\mathrm{T}-\mathrm{T}_{0}\right)\right. \\
\mathrm{R}_{\mathrm{N}}= & \mathrm{R}_{\mathrm{N}}\left(\mathrm{T}_{0}\right)[5],
\end{aligned}
$$

Equation (17) becomes by equation (20),

$$
\begin{aligned}
\frac{d}{d T}\left(\frac{V_{T} \ln n}{R}\right) & =2.079\left(\frac{0.08617 \mathrm{mV} /{ }^{\circ} \mathrm{K}-0.0000156 \mathrm{mV} /{ }^{\circ} \mathrm{K}}{R}\right) \\
& =\frac{0.1791 \mathrm{mV} /{ }^{\circ} \mathrm{K}}{R}
\end{aligned}
$$

Equation (18) becomes,

$$
\begin{aligned}
\frac{d}{d T}\left(\frac{V_{E B 1}}{R_{1}+R_{2}}\right) & =\frac{-1.5 \mathrm{mV} /{ }^{\circ} \mathrm{K}-750 \mathrm{mV}(0.0000006)}{\left(R_{1}+R_{2}\right)} \\
& =\frac{-1.50045 \mathrm{mV} /{ }^{\circ} \mathrm{K}}{R_{1}+R_{2}}
\end{aligned}
$$

Add the equation (8) and (9) to make zero temperature coefficients.

$$
\begin{gathered}
\frac{0.1791 \mathrm{mV} /{ }^{\circ} \mathrm{K}}{R}-\frac{1.50045 \mathrm{mV} /{ }^{\circ} \mathrm{K}}{R_{1}+R_{2}}=0 \\
R_{1}+R_{2}=8.38 R
\end{gathered}
$$

Equation (24) shows the values of resistance assuming " $R$ " value, which is independent of temperature variations.

\subsubsection{Determine the $R N$ in Terms of $(R 1+R 2) \&$ VrefN}

Equation (15) represents by room temperature using equation (24),

$$
\begin{aligned}
& \frac{V_{r e f}}{R_{N}}=\frac{54.065 m V}{R}+\frac{750 m V}{8.38 R} \\
& R_{N}=6.965 R \approx 7 R V_{r e f N}
\end{aligned}
$$

Where, ' $N$ ' is $1,2,3 \ldots$

Equation (25) shows the different ' $\mathrm{N}$ ' value of resistor for to get different ' $N$ ' reference voltages, which is independent of temperature variations but the value changes by voltage

\begin{tabular}{|c|c|c|c|}
\hline $\begin{array}{c}\text { Temperature } \\
(-40 \sim 125) \\
{ }^{\circ} \mathrm{C}\end{array}$ & FF & TT & SS \\
\hline $\begin{array}{l}\text { Pre Layout } \\
\left(\mathrm{V}_{\text {ref }}\right)(\mathrm{mV})\end{array}$ & $\begin{array}{c}553 \sim \\
530\end{array}$ & $551 \sim 527$ & $550 \sim 524$ \\
\hline $\begin{array}{l}\text { Post Layout } \\
\left(\mathrm{V}_{\text {ref }}\right)(\mathrm{mV})\end{array}$ & $\begin{array}{c}552 \sim \\
535\end{array}$ & $551 \sim 531$ & $549 \sim 529$ \\
\hline $\begin{array}{l}\text { Post Layout } \\
\left(\mathrm{V}_{\mathrm{DD}}\right)\left(\mathrm{V}_{\text {ref }}\right) \\
(0.8-1.2 \mathrm{~V})\end{array}$ & $\begin{array}{c}554 \sim \\
534\end{array}$ & $550 \sim 530$ & $547 \sim 527$ \\
\hline
\end{tabular}
dependence [6] shown in Fig. 2

\section{LAyOut Design AND Simulation RESUlts}

The three different reference voltages shown in Fig. 5 which is independent of supply varies from 0.8 to $1.8 \mathrm{~V}$ implemented in $0.18 \mu \mathrm{m}$ CMOS technology. The temperature independent of three different voltages is shown in Fig. 6. The layout design and comparison of pre and post layout simulation results is shown in Fig. 7 and table I.

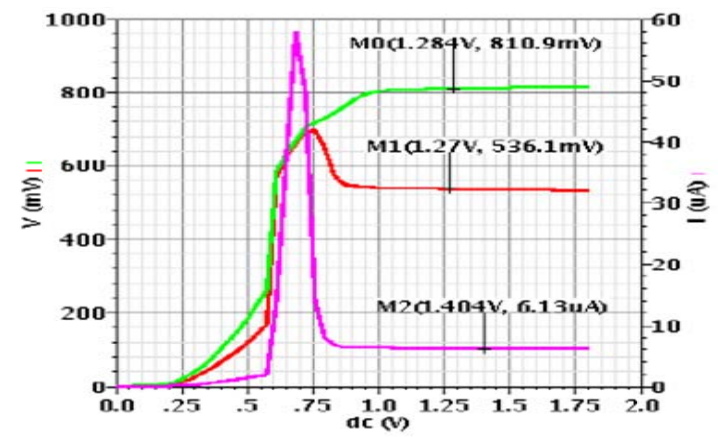

Fig. 5: Output Voltage and Current Varying with Supply Voltage at Typical Corner

Table 1: Comparison of Pre and Post Layout Results

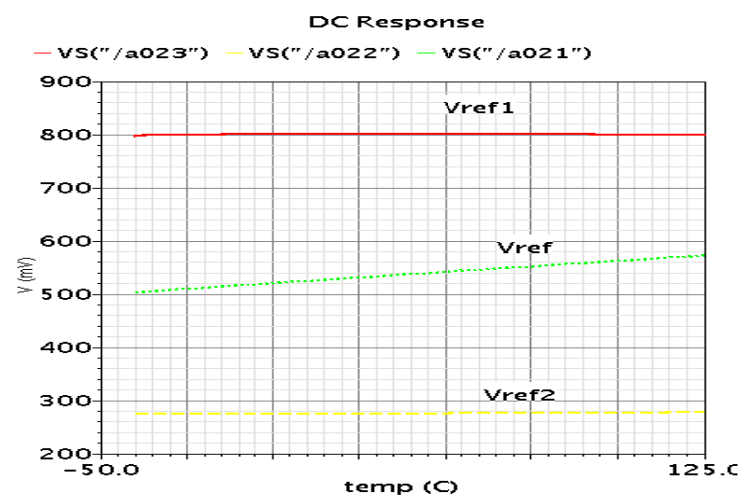

Fig. 6: Output Voltage and Current Varying Temperature at Typical Corner

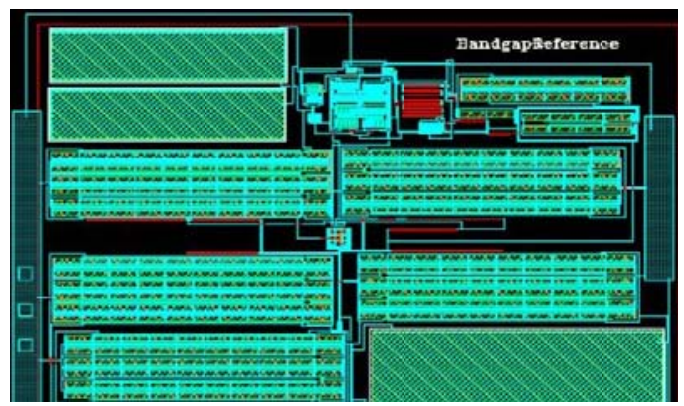

Fig. 7: Layout Design of Sub-1 V Bandgap Reference

\section{CONCLUSION AND FUTURE WORK}

Op-amp based low power CMOS bandgap voltage reference is designed and implemented with minimum supply of $0.8 \mathrm{~V}$ in $180 \mathrm{~nm}$ standard CMOS technology. The future work is to fabricate the chip in $180 \mathrm{~nm}$ CMOS technology. Also, implement the design by scaling down the channel 
length like $130 \mathrm{~nm}, 90 \mathrm{~nm}, 60 \mathrm{~nm}, 45 \mathrm{~nm}$ etc., in standard CMOS technology and tapeout the IC in different channel lengths. Compare the pre and post layout simulation with tapeout results .

\section{REFERENCES}

[1] Ka Nang Leung and Philip K.T. Mok, “A Sub-1-V 15-ppm $/{ }^{\circ} \mathrm{C}$ CMOS Bandgap Voltage Reference without Requiring Low Threshold Voltage Device," IEEE Journal of Solid-State Circuits, Vol. 37, No. 4, Pp. 526$530,2002$.

[2] P. Malcovati, F. Maloberti, M. Pruzzi, and C. Fiocchi, "Curvature compensated BiCMOS bandgap with 1-V supply voltage," Proceedings in ESSCIRC 2000:

[3] H. Banba, H. Shiga, A. Umezawa, T. Tanzawa, S. Atsumi, and K. Sakui, "A CMOS bandgap reference circuit with sub-1-V operation," IEEE Journal of Solid-State Circuits, Vol. 34, Pp. 670-674, 1999.

[4] B. Razavi, Design of Analog CMOS integrated Circuits. Tata Mc Graw Hill; 2001.

[5] Sedra/Smith, Microelectronics Circuits. Oxford.University Press, Inc. 2005.

[6] R. Jacob Baker, CMOS circuit design, layout and Simulation, WileyIEEE Press, 2005.

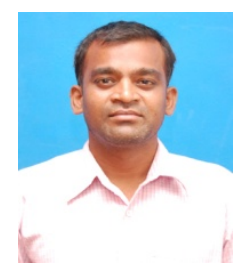

Arivazhagan $\mathrm{P}$ was born in Krishnapuram, vettikkadu (po), orathanadu (tk), thanjavur (dt), Taminadu,India614902 on july 28,1981 . About school life, from 1984 to 2000 studied from surrounding places where I am leaving. From there moved to Madras (now Chennai) and received the B.E degree in Electronics and Instrumentation Engineering from the University of Madras, TamilNadu in 2004. From 2003 to 2005, NCCT Limited, Chennai as a project staff involved with guidance for students. In 2006, received Advanced PG diploma in VLSI Design and worked as project trainee from Semiconductor Complex Limited (Vedant), Chandigarh, India under Cadence university Programme. From 2007 to 2011, joined as senior Project Assistant in Advanced VLSI Design Laboratory, Indian Institute of Technology (IIT), kharagpur, and involved with designing the ICs for high frequency applications and teaching assistant. I received MS (by research) in the department of Electronics and Electrical Communication Engineering from IIT Kharagpur in 2012. Spiritual achievement between 2010 to 2011 (at that time pursuing MS IIT-Kharagpur), succeeded based on six years spiritual truth love with "The Hindu religion God, Goddess" frequent temple visit. From Feb 2012 to July 2012 worked as an assistant Professor in Oxford Engineering College, Trichirappalli affiliated by anna university, chennai. Currently, working as an assistant professor in the department of Electronics and Communication Engineering, Kodaikanal Institute of Technology, Machur, Kodaikanal affiliated by anna university, Chennai. Achievements like gold medalist, Best project award, Best Paper award in ICVSP 2012. (e-mail: astm_codes@hotmail.com) 